\title{
Spatio-temporal Patterns in Grassland Communities
}

Tomáš Herben (herben@ibot.cas.cz)

Heinjo J.During (h.j.during@boev.biol.ruu.nl)

Richard Law (rl1@york.ac.uk)

\section{Approved by}

Ulf Dieckmann (dieckman@iiasa.ac.at)

Project Coordinator, Adaptive Dynamics Network

December 1999 


\section{Contents}

1 Introduction $\quad 1$

2 Spatio-temporal Patterns in Plant Communities 1

3 Externally versus Internally Generated Spatial Patterns $\quad 4$

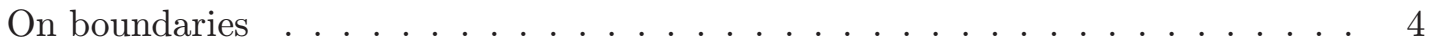

Covariation of pattern in community and environment . . . . . . . . . 5

4 Concepts in Spatio-temporal Processes in Plant Communities 5

Mosaic cycles and related patterns . . . . . . . . . . . . . . . 6

The carousel model . . . . . . . . . . . . . . . . . . . 7

Guild proportionality . . . . . . . . . . . . . . . 8

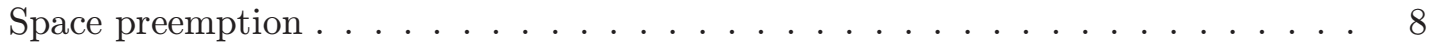

When are these models spatial? . . . . . . . . . . . . . . . . 9

5 Ergodic and Non-ergodic Communities $\quad 10$

6 Concluding Comments 12 


\author{
About the Authors \\ Tomáš Herben \\ Institute of Botany, Pruhonice, Czech Republic \\ Heinjo J. During \\ Department of Plant Ecology and Evolutionary Biology \\ University of Utrecht, Utrecht, The Netherlands \\ Richard Law \\ Department of Biology, University of York, York, UK \\ and \\ Adaptive Dynamics Network \\ International Institute for Applied Systems Analysis \\ Laxenburg, Austria
}




\title{
Spatio-temporal Patterns in Grassland Communities
}

\author{
Tomáš Herben \\ Heinjo J. During \\ Richard Law
}

\section{Introduction}

This chapter turns from the neighborhood processes of plants (discussed in Chapters 2 and 3 in Dieckmann et al. 2000) to the spatial patterns of plant communities. It provides some empirical background on what plant ecologists have learned about spatial patterns and their dynamics. In doing this, we examine criteria for distinguishing between patterns generated internally by biotic processes within communities and patterns generated externally by structural features of the abiotic environment. Although the focus of the chapter is primarily empirical, we describe several conceptual models that plant ecologists have considered while thinking about the dynamics of spatial pattern.

Spatial patterns play a pivotal part in plant community dynamics. When we look at these patterns, we see the outcome of a complex series of past events - including the biotic processes of birth, death, and movement, and some element of chance-together with the structure of the abiotic environment. At the same time, we see a baseline on which future events depend; how spatial patterns unfold through time depends on their previous states. Through these dynamics, large-scale patterns emerge that cannot be predicted from local processes, because these processes are coupled to the global pattern of the community. This coupling will become a major theme in later chapters of the book.

\section{Spatio-temporal Patterns in Plant Communities}

Ecologists have long recognized the importance of spatial pattern in terrestrial plant communities and have devoted considerable effort to documenting the patterns that occur (Blackman 1935; for reviews see Pielou 1968; Greig-Smith 1983; Kershaw and Looney 1985). The locations of plants in such communities can be thought of as patterns in a two-dimensional space. A pattern can be recorded as a map of points (Figure 1) if there is plenty of space between individuals at ground level, as in woodlands and desert communities. Alternatively, a pattern can be recorded as a map of clumps of finite area (Figure 2) if conspecifics cannot be readily separated from one another and the edges of clumps are distinct (Pielou 1968). If, as is often the case, clumps do not form clear boundaries, spatial location can be measured to the level of discrete cells in a lattice (e.g., Thórhallsdóttir 1990a; Herben et al. 1993), as shown in Figure 3. When dealing with multispecies plant communities, individuals or clumps can be indexed by species and if necessary by other qualities as well.

Much of the early research on spatial pattern was designed to establish whether plants of a single species are independently distributed in space or, if not, whether the departure 


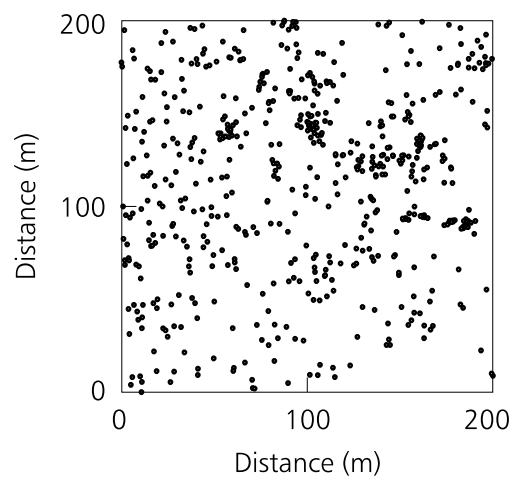

Figure 1 Locations of longleaf pine trees in an area $200 \mathrm{~m} \times 200 \mathrm{~m}$. Source: Cressie (1991).
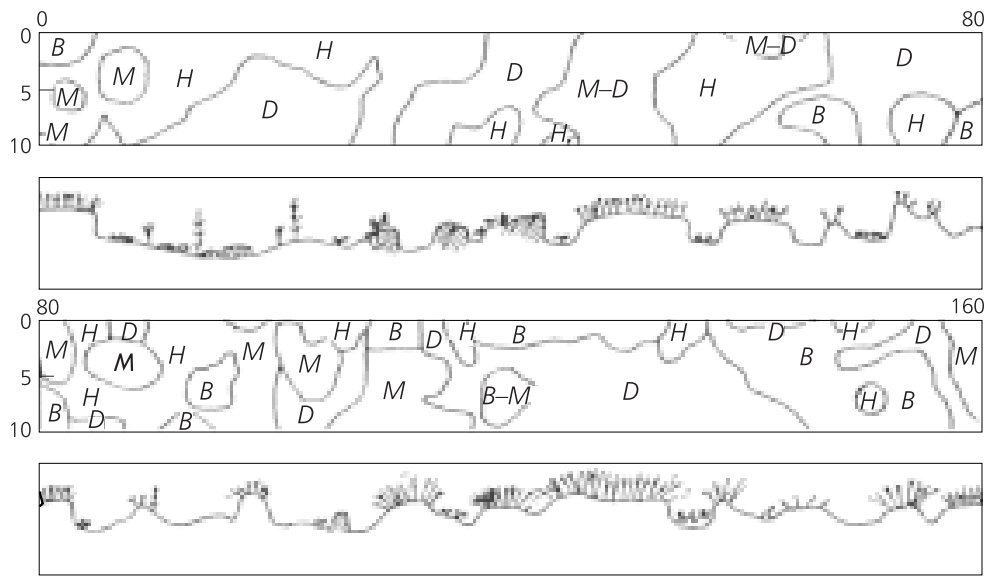

Figure 2 Patchy spatial structure of a $160 \mathrm{~cm} \times 10 \mathrm{~cm}$ plot in a Breckland grassland. Abbreviations: $\mathrm{B}=$ Building phase; $\mathrm{M}=$ Mature phase; $\mathrm{D}=$ Degenerate phase; $\mathrm{H}=$ Hollow phase. Source: Watt (1947).

from randomness is toward overdispersion (regularity) or underdispersion (clumping). In formal terms, this work tests the null hypothesis that spatial pattern is completely random, that is, generated by a homogeneous spatial Poisson process (see Chapter 5 in Dieckmann et al. 2000). This research showed that patterns are often highly nonrandom (Greig-Smith 1983; Kershaw and Looney 1985). In grassland communities, departures from randomness are typically toward clumping (see, for instance, the spatial pattern of the grass Nardus stricta in Figure 3). Such clumping is not surprising in view of the importance of clonal growth among the grasses and other taxa that dominate grassland communities, because one property of clonal growth is that offspring tend to be placed close to the parent plant. However, clustering is by no means inevitable; in other kinds of communities, such as those in arid environments, overdispersion can sometimes be detected. In these arid environments, plants that occur close to one another may run an increased risk of death due to competition or allelopathy (Phillips and MacMahon 1981).

Although nonrandomness is unsurprising, and deemed uninteresting in some quarters, it has a crucial bearing on the dynamics of plant communities. Processes in plant communities take place in small neighborhoods (see Chapter 2 in Dieckmann et al. 2000); in addition to random differences in neighborhoods from one plant to another, the nonrandom spatial patterns often observed in the field lead us to expect systematic differences in neighborhoods. Such spatial structure is very likely to affect the births and deaths that lie at the heart of community processes, and to ignore it would be to miss a critical coupling in the dynamics. Nonetheless, surprisingly few researchers have studied the dynamics of spatial pattern in plant communities. Plant ecologists interested in temporal dynamics 


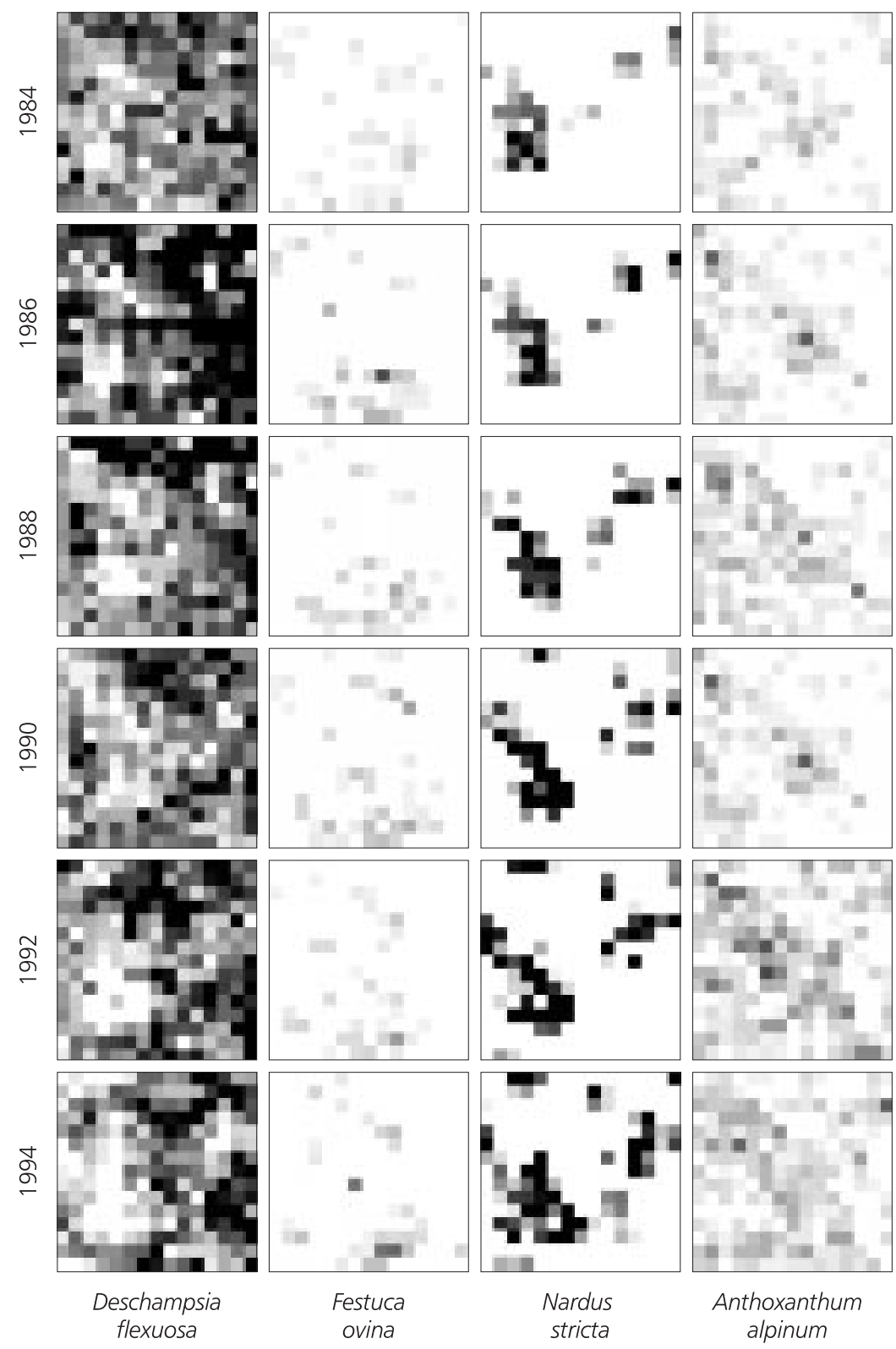

Figure 3 A spatio-temporal process in a montane grassland community at the Krkonoše, Czech Republic. The plot $(50 \mathrm{~cm} \times 50 \mathrm{~cm})$ is divided into $15 \times 15$ cells and is dominated by four grass species. The depth of shading in each cell is proportional to abundance; white indicates absence of the species. Source: Law et al. (1997).

have until recently turned more to animal ecology for inspiration (for a review, see Harper 1977), and the innate mobility of many animals means that spatial pattern is a less obvious feature of these communities.

A notable early exception was the work of Watt (1960). Starting in the 1930s, Watt tracked the fine-scale spatial structure of grassland communities in the Breckland in England every year for several decades, generating the kind of data needed to gain insight into spatio-temporal processes in plant communities. However, few researchers followed his lead; a survey of permanent plots in Britain (Hill and Radford 1986) did not report a single study (apart from forestry studies) containing spatial patterns of multispecies communities through time.

The situation is now changing as data on spatio-temporal processes in grassland and other kinds of communities are becoming available. Among these are data on calcareous 
grasslands from Öland, Sweden (van der Maarel and Sykes 1993; Sykes et al. 1994); results from several independent studies of grasslands in Britain (e.g., Mitchley 1988; Thórhallsdóttir 1990a; Law et al. 1993; McLellan 1995), limestone grasslands in the Netherlands (Willems et al. 1993; Sykes et al. 1994; Mitchley and Willems 1995), savanna grasslands in North Carolina (Sykes et al. 1994), and mountain grasslands of Central Europe (Herben et al. 1993, 1995); and the spatio-temporal pattern of bryophytes, that is, mosses and liverworts (During and Lloret 1996). Figure 3 shows a representative time series of spatial pattern in a grassland community.

Perhaps the most striking result from these studies has been the high rate of turnover of species at small spatial scales (Thórhallsdóttir 1990a; Sykes et al. 1994; McLellan 1995). For example, in the Krkonoše mountain grasslands, no species showed significant temporal autocorrelations at a given location in space for time lags greater than five years (Herben et al. 1993, 1995); in savanna grasslands and grasslands in Sweden and the Netherlands the cumulative number of species in microsites more than doubled over a time interval of five years. The bryophyte communities also showed strong microscale turnover, whereas at larger spatial scales little change was observed. In general, macroscopic structures change relatively little despite the fast dynamics of these communities (Pärtel and Zobel 1995; van der Maarel 1996).

In sum, the empirical research has shown that spatial patterns in plant communities are often highly nonrandom and far from fixed, even over short periods of time.

\section{Externally versus Internally Generated Spatial Patterns}

Here we turn to the question of what drives the nonrandom and rapidly changing spatial patterns in grassland communities.

\section{On boundaries}

The first important issue is whether nonrandom spatial patterns are generated by processes operating within the community or whether the pattern is imposed on the community from outside. Externally generated patterns are not central to the perspective of this book (the dynamics of imposed patterns are far less intricate than those of emergent patterns), but internally generated patterns certainly are. The distinction between the two is crucial and immediately raises the question of how to define internal and external in a conceptually consistent way.

In some cases the distinction appears clear-cut. Some patterns are generated by factors that, for practical purposes, are independent of the vegetation, such as the depth of soil on rock outcrops (Burgman 1987; Ohsawa and Yamane 1988). Such factors are usually deemed external: they affect the vegetation but are not affected by it. Even here it is arguable that the time period could be extended sufficiently for the pattern-generating mechanism to be affected by the vegetation dynamics, as soil development is ultimately influenced by the plant community.

In other cases, appropriate boundaries (or scales) in space and time are less easily decided and it is more difficult to distinguish between external and internal. Consider, for instance, the effects of large vertebrate grazers on grassland vegetation. In savanna or prairie ecosystems (e.g., Collins and Glenn 1988), such grazers form an obvious part of the ecosystem and are responsible for much of the pattern in the vegetation. At the same time, the changes that occur in the spatial pattern of the vegetation over the course of time 
feed back to the behavior of the grazers. Here the coupling is mutual - grazer behavior affects spatial patterns of vegetation, which affect grazer behavior - and it makes sense to think of the grazers as internal to the system. In comparison, the fine-grained structure of small, dense tussocks of Nardus stricta intermingled with loose turfs of Deschampsia flexuosa in Czech mountain grasslands (Herben et al. 1993; see Figure 3) has hardly any effect on the behavior of the grazers, even though the vegetation pattern itself may strongly depend on their action. Here the feedback loop is broken, and the grazers may be thought of as external to the system as far as the vegetation dynamics are concerned. Detailed knowledge of a system is needed to determine the appropriate boundaries, and such knowledge is often lacking.

\section{Covariation of pattern in community and environment}

One might hope to settle the issue in practice by looking at the extent to which spatial pattern in a plant community correlates with heterogeneity in the physical and chemical environment. Obviously, pattern in the environment does exist and is, at least in some cases, correlated with the pattern in vegetation (Stark 1994). However, plants change their environment in various ways, and the presence of environmental heterogeneity does not preclude the possibility that the heterogeneities might have been generated by the plants themselves. A good example of how pattern in the environment depends on vegetation is the horizontal light variation in forests (Pearcy et al. 1994) or in grasslands (Silvertown and Smith 1989; Tang and Washitani 1995).

Another example is the fine-scale correlation of vegetation and nutrient availability (Jackson and Caldwell 1993; Robertson and Gross 1994). Such heterogeneity is expected to change through time, at least at small scales, due to continuous uptake by plants and microorganisms and input by weathering and decomposition (Stark 1994). Here again, environmental heterogeneity can be said to be internally generated by plants themselves. A nice example is given by Schlesinger et al. (1996), who found 35-76\% of the variation in soil nitrogen in grasslands of the Chihuahuan Desert of New Mexico to be within $20 \mathrm{~cm}$ of individual plants. This is likely to be the result of local accumulations of soil nitrogen under Bouteloua eriopoda, a perennial bunchgrass. Although relatively little is known about the spatial and temporal scales of below-ground heterogeneity, the available data show below-ground patterns with scales similar to those of vegetation above ground and short-term feedbacks between vegetation and soil.

Correlations between plant pattern and environmental pattern are widespread, but we have to go beyond these correlations to understand the causal pathways involved. Experiments that manipulate the plants and test for changes in the environment are needed to check for the existence of feedbacks. In some cases these experiments are straightforward; for example, removing a plant has an immediate effect on the light environment in its neighborhood. In other cases, such as plant-soil relationships, appropriate manipulative experiments are more difficult to design and perform. However, until such feedbacks are ruled out, we cannot conclude that the spatial pattern we observe in a community is imposed on it externally by the environment.

\section{Concepts in Spatio-temporal Processes in Plant Communities}

Plant ecologists have been more concerned with documenting spatial patterns and how they change through time than with studying and understanding their dynamics in formal 


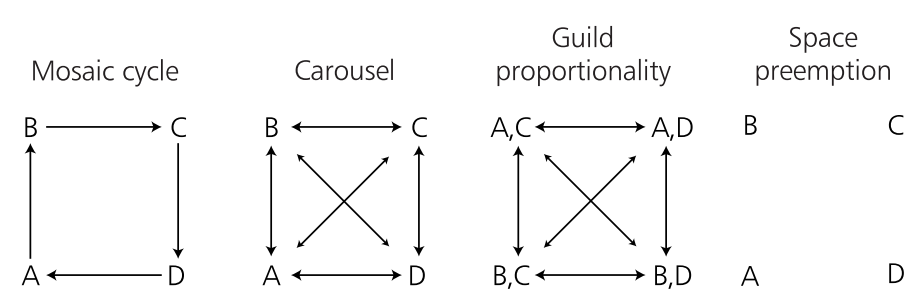

Figure 4 Schematic depiction of four models of plant community dynamics. A, B, C, and D are species and arrows indicate possible transitions between states. In the guild proportionality model, $\mathrm{A}$ and $\mathrm{B}$ are in the same guild (as are C and D) and do not occur together.

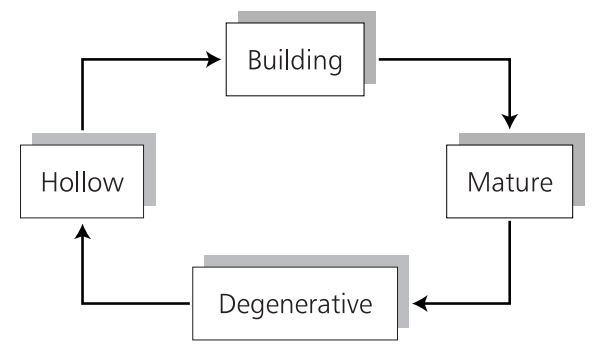

Figure 5 Cyclic sequence of patch states occurring at a single location corresponding to the patch states in a Breckland grassland (see Figure 2).

models. With a few notable exceptions (e.g., Pacala et al. 1996), this applies as much to recent research on spatio-temporal patterns as it does to earlier work on "snapshots" of spatial patterns. Nonetheless, certain kinds of pattern dynamics have led to informal conceptual models in the minds of ecologists, and at least one of these, the mosaic cycle, has become quite influential in ecological thinking. Here, we outline four conceptual models of vegetation dynamics; Figure 4 summarizes their main features. The data we focus on come mainly from grasslands because these communities have a relatively simple structure and because, perhaps for this very reason, most studies on pattern and process have been conducted in grasslands.

\section{Mosaic cycles and related patterns}

The mosaic cycle stems from work on a variety of grassland, heathland, and woodland communities; the data were first synthesized by Watt (1947) in a famous paper on pattern and process in the plant community. Watt noted, for example, the patchy structure of a grassland in the Breckland (see Figure 2). The grass Festuca ovina plays a prominent part in this community: when a seedling grows and develops into a young vigorous plant, soil accumulates around it and forms a hummock. This building phase is followed by a mature phase, during which the original plant becomes separated into small fragments, which later become colonized by lichens, leading to the degenerative phase as the hummock becomes eroded. Eventually the cycle returns to its starting point, the hollow phase. These and other data led Watt to picture plant communities as spatial mosaics of patches. The sequence of events at a single spatial location is cyclic, going through the building phase to maturity to degeneration to the hollow phase, as shown in Figure 5. Watt (1947) did not himself refer to this as a mosaic cycle, but the term has come to be associated with cyclic turnover of the state of local spatial patches (Remmert 1991; van der Maarel 1996).

A key notion in the mosaic cycle is environmental change due to the presence of particular plant species. This change produces conditions that are favorable to a set of species different from those resident at the site. In many cases, the change is closely linked to the life cycle of one dominant species, whose morphology thus forces a certain spatiotemporal pattern on the community. This is well illustrated by Watt's Breckland grassland, 
where the dominant species is Festuca ovina. The bunch grasses in Spanish "steppe" areas are another example; these grasses strongly affect light and moisture conditions in their immediate surroundings, leading to a characteristic zonation of bryophyte and lichen communities around them (Martinez-Sanchez et al. 1995). Although the individual grass tufts are long-lived, the dominant pattern of widely separated "bunches" gradually shifts due to tuft mortality and re-establishment elsewhere.

\section{The carousel model}

The carousel model is an outcome of research on species-rich limestone grasslands on the Swedish island of Öland carried out by van der Maarel and his colleagues. In these grasslands a large number of plant species are mixed at a fine spatial scale; in $0.01 \mathrm{~m}^{2}$ quadrats the mean number of species present was approximately 16 in 1986 (van der Maarel and Sykes 1993). What is particularly interesting about the dynamics of this system is the rapid turnover of species at a fine spatial scale over subsequent years. Tracking the species composition of the same quadrats over time, they found that the cumulative number of species was 24 five years later, yet through the period the number actually present remained at about the 1986 level (Table 1). This led van der Maarel and Sykes (1993) to suggest that each site can be colonized by most of the species present in the community.

To interpret their observations, van der Maarel and Sykes (1993) introduced the metaphor of a carousel (or merry-go-round), the idea being that species move around the spatial region occupied by the community and sooner or later reach every location in the space. It is implicit in their model that there is no particular order in which species appear; in other words, the current state of any microsite is essentially independent of its previous state. The carousel model thus differs from the mosaic cycle in that there is no definite order in which species replace one another at a given location.

Rapid turnover of species of the kind envisaged in the carousel model appears to be a common phenomenon in grassland systems (for a review, see van der Maarel 1996). A similar process at a much smaller scale is evident in ephemeral bryophytes. They occur in the soil diaspore bank (in an inactive state) in large numbers, but appear above ground only for a short time after some kind of small-scale disturbance (e.g., frost heaving in spots with locally reduced cover of their larger plant competitors, worm casts, ant hills). The plants live just long enough to produce new diaspores, which are little dispersed in space and thus remain in the local diaspore bank. The fact that such diaspores have been found nearly everywhere in the soil of grasslands, forests, and other communities (During and Ter Horst 1983; During et al. 1988) suggests that in the long run each microsite in the communities will have been such a gap; the actual aboveground pattern of these species then reflects shifting patterns in vegetation structure and animal activities.

Because the carousel model is a simplified view of the community dynamics, it should not be expected to give a detailed description of processes in species-rich communities. Further analyses on the data set obtained by van der Maarel and Sykes (1993) indeed showed that some microsites tended to be consistently species-rich, whereas others were consistently species-poor (Wilson et al. 1995a; van der Maarel et al. 1995). This may be indicative of some fine-scale niche differentiation, or perhaps just a high persistence of species with slower dynamics. It is unclear to what extent the turnover of species is really generated within the community by processes such as limited module life span and competition. Indeed, spatio-temporal patterns of communities with structure imposed externally by random local disturbances may be very similar to those of communities with structure generated internally. 
Table 1 Total and cumulative number of species in $0.01 \mathrm{~m}^{2}$ and $0.25 \mathrm{~m}^{2}$ quadrats in an alvar grassland on the island of Öland, Sweden. All values are means of 40 observations. Source: van der Maarel and Sykes (1993).

\begin{tabular}{lrrrrrl}
\hline Quadrat size & 1986 & 1987 & 1988 & 1989 & 1990 & 1991 \\
\hline Mean number of species per quadrat & 16.3 & 13.9 & 14.9 & 14.5 & 12.1 & 14.9 \\
$0.01 \mathrm{~m}^{2}$ & 26.1 & 25.8 & 26.8 & 25.9 & 27.1 & 27.3 \\
$0.25 \mathrm{~m}^{2}$ & 16.3 & 19.0 & 20.6 & 21.7 & 22.8 & 24.1 \\
Cumulative number of species in quadrat since & 1986 & & & \\
$0.01 \mathrm{~m}^{2}$ & 26.1 & 29.3 & 30.5 & 31.5 & 32.6 & 33.6 \\
$0.25 \mathrm{~m}^{2}$ & & &
\end{tabular}

\section{Guild proportionality}

The concept of guild proportionality was put forward by Wilson and Roxburgh (1994) to explain combinations of species co-occurrence in a lawn in New Zealand. Using a point sampling system, they were able to identify groups of species that tended to exclude one another, as opposed to species from different groups that did not do so. For example, at locations where two species were present, it was more likely that one would be a grass and one a forb (herbaceous dicotyledon) than that both would be grasses or both forbs. They interpreted this as being due to a system of several guilds of species, each of which locally saturates to a fixed low number of species from a larger species pool. Only two guilds were identified in the community studied by Wilson and Roxburgh (1994), perhaps because of the low statistical power of the technique used. By referring to the groups as "guilds," they were implying that the nonrandom co-occurrence of species within guilds is due to competitive exclusion. Guild proportionality prevents the system from attaining all combinatorially possible species sets locally, even though the species may have fast dynamics at a small spatial scale. Like the carousel model, no constraint is imposed on the order in which species replace one another locally, but in contrast to it, there is an additional constraint that some combinations of species are more likely than others; in the extreme, some combinations could be absent altogether.

How general a feature of grasslands guild proportionality is remains to be established; moreover, techniques for establishing the guild structure of a community are themselves a matter of debate (Goldberg 1995; van der Maarel et al. 1995; Wilson et al. 1995a). In our opinion, the evidence for the existence of such a rigid guild structure within grassland communities is rather weak. Still the guild proportionality model of community structure is a feasible notion and cannot be dismissed on the basis of the evidence currently available.

\section{Space preemption}

Sometimes "ownership" of a site confers a competitive advantage on the owner and leads to continued occupation of the site by a single (set of) species. An example of this is found in certain peat bogs that show a pronounced mosaic of elevated sites (hummocks) and depressions (hollows), each with a specific set of species. Analysis of soil cores shows that such occupation may last for several centuries at least, and there are demonstrated cases of it lasting for several millennia (Casparie 1969, 1972). As in the mosaic cycle, the species occupying the site induce environmental change there; but in contrast to the mosaic cycle, the environmental change favors the species already present. The presence of a plant species thus feeds back, producing conditions that support the species already occupying the site.

As far as we know, plant ecologists have not yet given a name to this process; we refer 
to it as space preemption. Founder events in communities with space preemption have major effects on subsequent spatial patterns and maintain a remarkably constant spatial pattern for components of the community. Space preemption is quite different from all of the earlier models because there is little turnover in species composition at each location in space and the species' spatial distributions are determined primarily by random effects at the beginning of the habitat colonization.

It is not known how common space preemption is; even in the case of peat bogs, some early research suggested a mosaic cycle as an appropriate model (Watt 1947), although this was shown to be incorrect by later observations. In most communities, founder effects are probably weakened by plant mortality and subsequent establishment of shoots or seedlings of other species.

\section{When are these models spatial?}

At their simplest, the models discussed here are concerned only with events at a single site. Depending on the model, the sequence of states may be random or cyclic, or there may be no change in state at all. In the context of this chapter, it is important to know the extent to which events at one site interact with those at neighboring sites. Such a coupling may then generate large-scale spatio-temporal structure in the community.

The importance of interactions between neighboring sites depends on the specific processes that drive the dynamics. In the case of the mosaic cycle, Watt (1947) made it quite explicit that spatial coupling of events in neighboring patches played a major role in the dynamics. Some degree of neighbor dependence is also known from the gap-phase dynamics of forests; data from the Barro Colorado tropical forest (see Chapter 13 in Dieckmann et al. 2000) show that, where a gap occurs, additional gaps are likely to form in its immediate neighborhood.

In the carousel and guild proportionality models, no specific assumption is made about dependence of dynamics at one site on the state of its neighborhood. If species taking part do not produce daughter plants on stolons or rhizomes [e.g., the bryophytes of During et al. (1988) or annual species of the calcareous grassland species of van der Maarel and Sykes (1993); see also Wilson et al. (1995a)], the spatial coupling is likely to be rather weak. Clonal growth, however, often constrains the species that appear at the site to those that occur in neighboring sites and strengthens the spatial coupling (Law et al. 1993; Herben et al. 1995). In the space preemption model, it is hard to envisage any major spatial coupling; the local state at a given microsite is determined by initial conditions at that microsite only.

In some cases, spatial coupling is imposed by an external, but spatially homogeneous, factor: the very clear wave-like pattern in coastal heaths in westernmost France, for instance, seems to be caused by the continuous effect of strong westerly, salt-laden winds from the sea, causing gradual mortality of branches on one side with continuing growth on the other side. A similar process of wave-like pattern formation due to clonal growth of plants was described by Watt in his classic 1947 paper (see discussion of dwarf Callunetum). Similar patterns may be generated by moisture retention of dryland vegetation growing on a sloping terrain. This vegetation tends to form horizontal stripes that slowly move up the slope, apparently due to the capture of runoff water from the bare stripes in between by specialized pioneer species growing at the upper rim of the stripes (Cornet et al. 1988).

The data thus show that spatial dependence is a common property of those communities to which the mosaic, carousel, and guild proportionality models apply, although it is not necessarily implied by these models. A possible classification of some field systems 
Table 2 Classification of several field systems into different underlying models

\begin{tabular}{lll}
\hline Underlying model & Weak spatial coupling & Strong spatial coupling \\
\hline Mosaic cycle & $\begin{array}{l}\text { Spanish "steppe" } \\
\text { (Martinez-Sanchez et al. 1995) }\end{array}$ & $\begin{array}{l}\text { Regeneration waves } \\
\text { (Watt 1960) }\end{array}$ \\
Carousel & $\begin{array}{l}\text { Soil bryophytes } \\
\text { (During et al. 1988) }\end{array}$ & $\begin{array}{l}\text { Perennial grasslands } \\
\text { (van der Maarel and Sykes }\end{array}$ \\
& $\begin{array}{l}\text { Alvar grassland } \\
\text { (van der Maarel and Sykes }\end{array}$ & 1993) \\
& $1993)$ & \\
Guild & - & $\begin{array}{l}\text { Mown grassland } \\
\text { proportionality }\end{array}$ \\
Space preemption & (Wilson and Roxburgh 1994) \\
& Hummock and hollow of & - \\
\hline
\end{tabular}

into classes with strong and weak spatial coupling is suggested in Table 2; it should be understood that, with knowledge as it stands at present, this can be no more than a tentative classification.

\section{$5 \quad$ Ergodic and Non-ergodic Communities}

The obvious way to distinguish communities according to the models discussed in Section 4 is to look at the sequence in which species appear and disappear at some spatial location over the course of time. The carousel model, at its simplest, envisages that the location will be visited by every species in the community as time progresses and that there will be no particular order in which the species occur. This is in contrast to the mosaic cycle, in which species appear and disappear at the location in a particular sequence that is repeated over and over again. A community in which space preemption operates is quite different because the species composition is frozen in time; the fact that species differ from one location to another is not reflected at a single location followed through time. Guild proportionality is different again, as the states a site can take are restricted; states involving combinations of incompatible species are less frequently found than those of compatible species.

These distinctions lead to an issue of what, if any, plant community can be said to satisfy an assumption of ergodicity (see Box 1 for an introduction to the notion of ergodicity). The assumption of ergodicity is that sample averages equal ensemble averages; roughly speaking, this means that the average long-term state of a plant community at a single location is the same as its average state across different locations at a single time.

There are two reasons for raising the issue of ergodicity. The first is to clarify an important distinction between some of the conceptual models above. A community operating under the rules of the carousel model is ergodic, at least in the simplest form of the model. Given a long enough period of time, each location will be visited by each species in proportion to its abundance at different locations in space. This is in contrast to a community to which space preemption applies. Here, the community cannot be ergodic; the time average at a single location will be nonzero only for the single species that reached the location first, whereas the ensemble average will have nonzero values for all the species in the community. A community with a mosaic cycle is ergodic but has an additional property that the states follow one another in a specified sequence. In the presence of guild proportionality, ergodicity would again apply, but the tendency for certain species not to occur together would be reflected by correspondingly low values for the probability 


\section{Box 1 Ergodicity}

Ergodicity (from the Greek: ergon, work; hodos, path) is a general mathematical notion. A process is said to be ergodic if and only if its sample average is equal to its ensemble average. But this is somewhat cryptic and requires explanation.

Think of a sample $f(u)$, which is a function of some variable $u$. We might, for instance, be thinking of population size through time, in which case the sample $f$ is population size and the argument $u$ is time. Arguments other than time are equally possible, for example, population size could be given as a function of spatial location at a single point in time. The sample average $S$ is given by

$$
S=\lim _{U \rightarrow \infty} \frac{1}{U} \int_{0}^{U} g(f(u)) d u .
$$

Notice that we think in terms of a function $g(f)$ of the sample rather than of the sample itself, as this makes the notion much more general; the function $g(f)$ can be thought of as a filter through which the sample is observed. At its simplest, we could have $g(f)=f$; in the case of population size as a function of time, $S$ is then the population size averaged over time. Another possibility is $g(f)=(f-\bar{f})^{2}$, in which case $S$ would be the variance of population size averaged over time. Taking the limit $U \rightarrow \infty$ gives the average of the sample as the variable $u$ becomes large.

To understand what is meant by the ensemble average, one needs to think of the probability $m(f)$ that the sample $f$ takes each state, for instance the probability that population size takes values $0,1,2, \ldots$, and so on. In the context of a stochastic process, one may think of many realizations of the sample that together form an ensemble; associated with this ensemble is a probability $m(f)$ for each state at some point in time. The function $m(f)$ is said to be the density of the measure of $f$, and the ensemble average $E$ is given by

$$
E=\int g(f) m(f) d f .
$$

Thus, for the process to be ergodic, (1) the sample average and ensemble average must exist, and (2) the relation $S=E$ must be satisfied.

Because it is a rather general notion, ergodicity can mean different things in different contexts. The context here is a spatio-temporal process of a plant community. The object of study is a multispecies time series, so the sample $f(u)$ is some measure of the population size - such as number or biomass - of each species at a particular location in space and the argument $u$ is time. There is no need to think of a filter through which to observe the sample, so we take $g(f)=f$, and the sample average is simply the long-term average over time of the population sizes. The ensemble average can be thought of in terms of the same stochastic process at many independent and equivalent locations; at some point in time, one can then envisage a probability associated with each state of the community over this ensemble. The ergodicity assumption is that the sample average equals the ensemble average.

of these states.

The second reason for raising ergodicity is methodological. Plant ecologists do not have long time series available and are unlikely to have them for many years to come. Under these circumstances, it is natural to ask what, if anything, could be learned about the average state in the long term from the state at many locations at a single time. The answer is that information from a single point in time can be used, but the ergodic assumption must be satisfied. Hara et al. (1995), for instance, were explicit in making this assumption when they estimated parameters in a model of tree growth in a multispecies community.

There are some caveats to keep in mind when applying the notion of ergodicity to plant communities. When making use of information across space to construct an ensemble average, the locations must be sufficiently remote from one another to be treated 
as independent. This criterion puts a lower bound on the size of the spatial region from which locations can be drawn to construct the ensemble average. At the same time the locations must be equivalent, otherwise they cannot be treated as replicates of the same stochastic process. This second criterion puts an upper bound on the spatial region; clearly, if we include locations in quite different environments, the stochastic process is going to be different. An analogous issue arises when following a community at a single location over time: if the time period is too long, changes in the environment are bound to occur. This is an intrinsic difficulty in using observations from permanent plots, since ecological conditions are never constant in time (van den Bergh 1979; Silvertown 1980). The matter is often complicated by the fact that the critical signals in the environment responsible for dominance shifts are not known and therefore no correction can be made for them (Stampfli 1995; Rosén 1995; Walker et al. 1994). In view of the trade-off between the criteria of independence and equivalence, how to choose an appropriate spatial and temporal scale in plant ecology is ultimately a matter of judgment.

\section{Concluding Comments}

Grassland communities often have fast dynamics at small spatial scales and show pronounced nonrandom spatio-temporal patterns. The extent to which these dynamics can be said to be internally generated depends in part on where system boundaries are drawn. At present, information on which to establish appropriate system boundaries is in short supply (grids with cells of only a few square centimeters, study durations of a few years), and the mechanistic understanding of the system being studied is often insufficient. On the other hand, there is nothing that strongly contradicts the notion of structure being generated internally, and there are various properties of birth and death processes that lead naturally to development of nonrandom spatial pattern.

The literature on plant ecology contains several informal models of how plant community dynamics may proceed in space and time; we have identified in particular the mosaic cycle, the carousel model, guild proportionality, and space preemption. These models have contrasting consequences for local turnover of species and implications for the assumption of ergodicity. However, understanding of the spatial component of plant community dynamics is as yet very limited and stands to be greatly enhanced by the current growth in mathematical knowledge of spatio-temporal processes of the kind described in the chapters that follow.

Acknowledgments Figure 1 was reprinted by permission of John Wiley \& Sons Inc. from Statistics for Spatial Data by N.A.C. Cressie, Copyright (c) 1991, John Wiley \& Sons. Figure 2 was reprinted by permission of the British Ecological Society. 


\section{References}

Blackman GE (1935). A study by statistical methods of the distribution of species in grassland association. Annals of Botany 49:749-777

Burgman MA (1987). An analysis of the distribution of plants on granite outcrops in southern Western Australia using Mantel tests. Vegetatio 71:79-86

Casparie WA (1969). Bult- und Schlenkenbildung in Hochmoortorf. Vegetatio 19:146-180

Casparie WA (1972). Bog development in Southeastern Drente, The Netherlands. Vegetatio 25:1271

Collins SL, Glenn SM (1988). Disturbance and community structure in North American prairies. In Diversity and Pattern in Plant Communities, ed. During HJ, Werger MJA, Willems JH, pp. 131-143. The Hague, Netherlands: SPB Academic Publishing

Cornet AF, Delhoume JP, Montana C (1988). Dynamics of striped vegetation patterns and water balance in the Chihuahuan desert. In Diversity and Pattern in Plant Communities, ed. During HJ, Werger MJA, Willems JH, pp. 221-231. The Hague, Netherlands: SPB Academic Publishing

Cressie NAC (1991). Statistics for Spatial Data. New York, NY, USA: Wiley

Dieckmann U, Law R, Metz JAJ, eds. (2000). The Geometry of Ecological Interactions: Simplifying Spatial Complexity. Cambridge, UK: Cambridge University Press

During HJ, Lloret F (1996). Permanent grid studies in bryophyte communities. I. Pattern and dynamics of individual species. Journal of the Hattori Botanical Laboratory 79:1-41

During HJ, Ter Horst B (1983). The diaspore bank of bryophytes and ferns in chalk grassland. Lindbergia 9:57-64

During HJ, Brugues M, Cros RM, Lloret F (1988). The diaspore bank of bryophytes and ferns in the soil in some contrasting habitats around Barcelona, Spain. Lindbergia 13:137-149

Goldberg DE (1995). Generating and testing predictions about community structure: Which theory is relevant and can it be tested with observational data? Folia Geobotanica et Phytotaxonomica 30:511-518

Greig-Smith P (1983). Quantitative Plant Ecology, 3rd ed. Oxford, UK: Blackwell

Hara T, Nishimura N, Yamamoto S (1995). Tree competition and species coexistence in a cooltemperate old-growth forest in southwestern Japan. Journal of Vegetation Science 6:565-574

Harper JL (1977). Population Biology of Plants. London, UK: Academic Press

Herben T, Krahulec F, Hadincova V, Kovarova M (1993). Small scale spatial dynamics of plant species in a grassland community during six years. Journal of Vegetation Science 4:171-178

Herben T, During HJ, Krahulec F (1995). Spatio-temporal dynamics in mountain grasslands: Species autocorrelations in space and time. Folia Geobotanica et Phytotaxonomica 30:185196

Hill MO, Radford GL (1986). Register of Permanent Vegetation Plots. Abbots Ripton, UK: Institute of Terrestrial Ecology

Jackson RB, Caldwell MM (1993). The scale of nutrient heterogeneity around individual plants and its quantification with geostatistics. Ecology 74:612-614

Kershaw KA, Looney HH (1985). Quantitative and Dynamic Plant Ecology, 3rd ed. London, UK: Edward Arnold

Law R, McLellan A, Mahdi AS (1993). Spatio-temporal processes in a calcareous grassland. Plant Species Biology 8:175-193

Law R, Herben T, Dieckmann U (1997). Non-manipulative estimates of competition coefficients in a montane grassland community. Journal of Ecology 85:505-518

Martinez-Sanchez JJ, Casares-Porcel M, Guerra J, Gutierrez-Carretero L, Ros RM, HernandezBastida J, Cano MJ (1995). A special habitat for bryophytes and lichens in arid zones of Spain. Lindbergia 19:116-121

McLellan AJ (1995). Fine-scale Spatio-temporal Dynamics of a Limestone Grassland Community. $\mathrm{PhD}$ dissertation, University of York, York, UK

Mitchley J (1988). Control of relative abundance of perennials in chalk grassland in Southern England. III. Shoot phenology. Journal of Ecology 76:607-616

Mitchley J, Willems JH (1995). Vertical canopy structure of Dutch chalk grasslands in relation to their management. Vegetatio 117:17-27 
Ohsawa M, Yamane M (1988). Pattern and population dynamics in patchy communities on a maritime rock outcrop. In Diversity and Pattern in Plant Communities, ed. During HJ, Werger MJA, Willems JH, pp. 209-220. The Hague, Netherlands: SPB Academic Publishing

Pacala SW, Canham CD, Saponara J, Silander JA Jr, Kobe RK, Ribbens E (1996). Forest models defined by field measurements: Estimation, error analysis and dynamics. Ecological Monographs 66:1-43

Pärtel M, Zobel M (1995). Small-scale dynamics and species richness in successional alvar plant communities. Ecography 18:83-90

Pearcy RW, Chazdon RL, Gross LJ, Mott KA (1994). Photosynthetic utilization of sunflecks: A temporally patchy resource on a time scale of seconds to minutes. In Exploitation of Environmental Heterogeneity by Plants, ed. Caldwell MM, Pearcy RW, pp. 175-208. San Diego, CA, USA: Academic Press

Phillips DL, MacMahon JA (1981). Competition and spacing in desert shrubs. Journal of Ecology 69:97-115

Pielou EC (1968). An Introduction to Mathematical Ecology. New York, NY, USA: Wiley InterScience

Remmert H (1991). The mosaic-cycle concept of ecosystems-An overview. Ecological Studies 85:121

Robertson GP, Gross KL (1994). Assessing the heterogeneity of the belowground resources: Quantifying pattern and scale. In Exploitation of Environmental Heterogeneity by Plants, ed. Caldwell MM, Pearcy RW, pp. 237-254. San Diego, CA, USA: Academic Press

Rosén E (1995). Periodic droughts and long-term dynamics of alvar grassland vegetation on Öland, Sweden. Folia Geobotanic et Phytotaxonomica 30:131-140

Schlesinger WH, Raikes JA, Hartley AE, Cross AF (1996). On the spatial pattern of soil nutrients in desert ecosystems. Ecology 77:364-374

Silvertown J (1980). The dynamics of a grassland ecosystem: Botanical equilibrium in the Park Grass Experiment. Journal of Applied Ecology 17:491-504

Stampfli A (1995). Species composition and standing crop variation in an unfertilized meadow and its relationship to climatic variability during six years. Folia Geobotanica et Phytotaxonomica 30:117-130

Stark JM (1994). Causes of soil nutrient heterogeneity at different scales. In Exploitation of Environmental Heterogeneity by Plants, ed. Caldwell MM, Pearcy RW, pp. 255-284. San Diego, CA, USA: Academic Press

Sykes MT, van der Maarel E, Peet RK, Willems JH (1994). High species mobility in species rich plant communities: An intercontinental comparison. Folia Geobotanica et Phytotaxonomica 29:439-448

Tang Y, Washitani I (1995). Characteristics of small-scale heterogeneity in light availability within a Miscanthus sinensis canopy. Ecological Research 10:189-197

Thórhallsdóttir TE (1990a). The dynamics of a grassland community: A simultaneous investigation of spatial and temporal heterogeneity at various scales. Journal of Ecology 78:884-908

van den Bergh JP (1979). Changes in the composition of mixed populations of grassland species. In The Study of Vegetation, ed. Werger MJA, pp. 57-80. The Hague, Netherlands: Junk

van der Maarel E (1996). Pattern and process in the plant community: Fifty years after A.S. Watt. Journal of Vegetation Science 7:19-28

van der Maarel E, Sykes MT (1993). Small scale plant species turnover in a limestone grassland: The carousel model and some comments on the niche concept. Journal of Vegetation Science 4:179-188

van der Maarel E, Noest V, Palmer MW (1995). Variation in species richness on small grassland quadrats: Niche structure or small-scale plant mobility? Journal of Vegetation Science 6:741752

Walker MD, Webber PJ, Arnold EH, Ebert-May D (1994). Effects of interannual climate variation on aboveground phytomass in alpine vegetation. Ecology 75:393-408

Watt AS (1947). Pattern and process in the plant community. Journal of Ecology 35:1-22

Watt AS (1960). Population changes in acidiphilous grass-heath in Breckland, 1936-57. Journal of Ecology 48:605-629

Willems JH, Peet RK, Bik L (1993). Changes in chalk-grassland structure and species richness 
resulting from selective nutrient additions. Journal of Vegetation Science 4:203-212

Wilson JB, Roxburgh SH (1994). A demonstration of guild-based assembly rules for a plant community, and determination of intrinsic guilds. Oikos 69:267-276

Wilson JB, Sykes MT, Peet RK (1995a). Time and space in the community structure of a speciesrich limestone grassland. Journal of Vegetation Science 6:729-740 